\title{
Is the Social Integration Possible? The Role of Training among Young Adults Beneficiaries of Social Services Institutions
}

\author{
Marzanna Farnicka \\ University of Zielona Góra, Zielona Góra, Poland \\ Email: farniccy@gmail.com
}

Received 18 May 2016; accepted 12 July 2016; published 15 July 2016

Copyright () 2016 by author and Scientific Research Publishing Inc.

This work is licensed under the Creative Commons Attribution International License (CC BY).

http://creativecommons.org/licenses/by/4.0/

(c) (i) Open Access

\begin{abstract}
The aim of the research was to verify the effectiveness of the steps taken to activate social integration and the evaluation of the activities undertaken in that respect. The main assumption was that changes occur through the gaining of experience, its structuring and restructuring-particularly in the area of self-knowledge and evaluation of life opportunities. In the study it was presumed that the process of experiencing something in a new group and improving communication-related and professional skills could change the future prospects of an individual. Methods: The study involved 521 partizipants from two groups (unemployed and worked or studied). The following tools were used for the purpose of conducting the research: life experience questionnaire, questionnaire of the sense of control over events, tool for investigating expected changes and self-esteem scale. Results: The results pointed to the need for adjustment of preventive treatment to the current stage of development, as indicated by developmental tasks and future expectations. The observed and analysed changes in the dimensions of self-knowledge before and after participation in the project indicate that the project gave the respondents the improved ability to evaluate themselves realistically and closer contact with the reality, thus offering them an opportunity to change.
\end{abstract}

\section{Keywords}

Adulthood, Professional Skills, and Activation, Support of Development

\section{Introduction}

One of the main ideas of social policy assumes mutual interdependence of all the social groups in a given soci- 
ety (Weber, 2002). In many countries, social welfare ideas and tools concentrate on the process of activation and integration within the society. The main aim of activities undertaken in this field is to encourage active participation of individuals in the culture of a given society; this also relates to participating in forms of individual development offered by the state, such as education, work, community activities, and coming up with own proposals.

According to the theory of systemic family development, important factors affecting the psychological sphere are: individual activity, the impact of society and culture. Individual experience is gained through own activity of an individual in the family relations, in peer groups and in a broader social environment (Stratton, 2010). The relations force the response of an individual and, having been processed by the psychological system, they are incorporated in the individual's inner world (Cervone \& Pervin, 2013). Developmental changes occur firstly in the substructures of the individual's psychological system and then, as a result of changes in the inner system. Subsequently, these changes are manifested in the functioning of the developing individual or in the family and they initiate developmental changes in this micro-system. The assumptions about the changes occurring over a period of time and the relations between events important in life, cultural pressure and the cycle of family development and individual development are the basis for a hypothesis that subsequent experiences, which result from the activity of an individual and rebuild his/her psychological system, may influence every participant of an interaction and even shift a family into further cycles of its development (Erikson, 2004). On the basis of observation of functioning of some adults, their problems are related to the so called "risk developmental environment". The indicators of risk environment include the dysfunctional family with the presence of violence, addictions of parents, immigrant or reemigrant roots.

Psychological aspects of integration cannot overlook the so-called psychological stress/distress, the acculturative stress- a burden that a person experiences when encountering other cultures, the psychological disorientation experienced by people trying to adapt to radically different cultural environments (Berry, Poortinga, Breugelmans, Chasiotis, \& Sam, 2011). The important thing is the communication between cultures, the comparison of psychological differences between them, the effort to discover distinctive psychological features of individuals living in individual cultures, and at the same time the effort to discover the general laws governing all cultures (Banks, 2008). One of the models describing that root-taking and participation in culture may be the model was suggested by Bennett and developed on the ground of intercultural psychology (1986). Bennett (1986) described and analysed possible reactions to perceived cultural differences in the society dividing them into six stages. The first three stages are ethnocentric; further stages indicate the development of ethno-relativism, which enables a person to experience his or her own culture in the context of other cultures. Particular stages are connected with: (level/stage 1) noticing the differences between "us" and "them”, (level/stage 2) finding one’s own group identity (both in opposition to and in cooperation with the group that is considered to be the majority), (level/stage 3) acceptance of a given state of affairs, (level/stage 4) assimilation to the prevailing social order, (level/stage 5) creative adjustment to the situation (adaptation) and finally (level/stage 6) full integration, manifesting itself in creating the climate and conditions for the development of skills serving not only the purpose of survival in a given group, but also mutual intercultural exchange between "my group" and other groups.

The analysis of the cultural adaptation process carried out in the works of Pagani and Robustelli (2010) indicates that adaptation is a complex phenomenon consisting of two areas. The first area relates to the level of perception of differences in relation to one's own group and to the alien group. The second area relates to the level of acceptance for the difference between one's own group and the alien group. The researchers differentiate between two levels of functioning: low and high. At the low level of this complex thinking individuals use stereotypes and could be driven by emotions. The process of reality recognition is based on easy dimension: "alienstranger-different" or similar-from one's own group. People functioning in those dimensions on the high level think about their own group and about "alien" group in a non-simplistic, multi-aspectual manner (GrzymałaMoszczyńska, 2013).

\section{Theoretical Model for Study}

The point of departure for the development of the research model was the temporal model of developmental changes (Trempała, 2002b), in which the term temporal perspective is connected with the psychological dimension of time perception-from the past through the present into the future. The basic categories for the examining of temporal expectations are context and individual experience. The individual experience is organized within the framework of two systems: social knowledge patterns and self-knowledge patterns (Trempała, 2002a: p. 
187). In the field of social knowledge, two dimensions have been accentuated: the sense of normativity and generation gap. In the field of self-knowledge, such dimensions as self-esteem and sense of control over one's future are emphasized. In the analysed model, the processes of orientation towards the future, including motivation, planning and evaluation, are triggered on the basis of social knowledge and self-knowledge.

Another proposal, built around the notion of intention that contains all the motivational components leading to the implementation of the planned behaviour, is the concept of Ajzen (1991). The main assumption of that model is a proposition that usually (i.e. in an ordinary situation) people behave in accordance with their intentions. Those intentions change over time, as a result of changes in one of the three groups of factors that influence them. These factors are: attitudes, subjective norms and behavioural control. Attitudes are linked to the beliefs about the effects of a given behaviour, i.e. evaluation of the influence of a given behaviour for an individual or his/her environment. Ajzen (1991) differentiated between two aspects of the sense of control: real (real resources, such as time, money, education) and subjective-related to subjectively perceived control over the events (I am persistent or: I cannot cope). In both presented theoretical proposals similar elements determining future conduct were indicated. These are: social knowledge, sense of control, self-esteem, evaluation of the significance of events and definition of expected action.

\section{Research Aims}

\subsection{Research Subject}

The research material has been collected thanks to the project of active integration carried out by one of the District Family Aid Centres ${ }^{1}$. The main objective of the project was to raise the social status of the region inhabitants by equipping them with expected ${ }^{2}$ professional and social skills that would enable them to find employment. The implementation of the project was to bring about changes of those attitudes that hindered participation in social life; this was to be done by increasing motivation for self-initiated activities aimed at improvement of own life and professional situation and by improving the ability to cope in difficult situations for beneficiaries of the Family Aid Centres. The assumed aim of the project was being achieved through tasks which were the four components of active integration: educational activation (information offered during 12-hour workshops and individual meetings, e.g. legal advice, communication skills, time organization skills), health activation (medical advice and interventions-10 hours), professional activation (professional training and courses e.g. hairdressing course, beautician course, fork lift truck operation, driving license, each course lasting 60 hours), and social activation (organization of cultural events and meetings). The participants were obliged to avail themselves of at least three activation instruments from the first three components of active integration of their own choice. The social component was obligatory.

The research questions assumed the form of two hypotheses and related to assumptions about the potential existence of individual differences between social welfare beneficiaries and persons representing the so-called "social majority" (not covered with any form of social welfare), as well as the potential for the change of thinking about oneself as a result of the conducted training-impact (Banks, 2008; Lindquist \& Barret, 2008; Berry et al., 2011). Hypothesis 1. assumed the following wording: Persons qualified for the programme are characterized by lower self-esteem, lower sense of control over their lives, less positive evaluation of events and less positive expectations towards the future than persons from the so-called social majority (see Figure 1).

Hypothesis 2. was formulated: As a result of the conducted activities—known as "the project"—changes are going to occur among its participants in the form of increased self-esteem, increased sense of control over one's life, more positive evaluation of events and more positive expectations towards the future.

\subsection{Research Methods}

The following tools were used for the purpose of conducting the research: Life Experience Questionnaire, Questionnaire of the Sense of Control over Events, Tool for Investigating Expected Changes and Self-esteem Scale.

The Life Experience Questionnaire (Boszkiewicz, 1997) investigates the assessment of influence of certain

\footnotetext{
${ }^{1}$ The project was carried out in the years 2010-2013 and funded by the European Social Fund (Sub-measure 7.1.2.). The project with training lasted 3 months and was prepared as part of implementation of the grant entitled "Action for the social integration of inhabitants of the Zielona Góra district” in the years 2008-2013 financed by the EU from the Human Capital Development fund.

${ }^{2}$ Expected-according to the list obtained in co-operation with the Employment Office.
} 
Time 1

Before training

\begin{tabular}{|l|}
\hline Skills \\
Self-esteem \\
Control \\
Evaluation \\
\hline
\end{tabular}

Future-related expectations thinking about changes 1
Time 2

After training

\section{Skills}

Self-esteem

Control

Evaluation

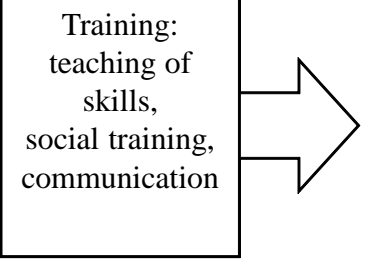

Future-related

expectations thinking about changes 2

Figure 1. Variables and expected changes after training (model of study).

events on the life of an individual. The questionnaire used for the research contained 20 questions concerning events from young adulthood, such as choice of life partner, graduation from school, undertaking the first job, loss of job, birth of a child, moving into one's own apartment. Respondents defined the importance of a particular event (e.g. first work, graduation) on a 7-point scale, where 6 was extremely positive, 5-moderately positive, down to 0 meaning the evaluation of a certain life event as an extremely negative (Cronbach's Alpha for that tool was .76).

The Questionnaire of the Sense of Control over Events (Trempała, 2002a) enables the investigation of the respondents' sense of control over the selected aspects of life (professional life, family life, social life, economic conditions, own health, own appearance, free time). The respondents stated how often they had the sense of control over various spheres of life in a 1 to 5 scale, where 1 meant "I do not have any influence" (almost never), 2-rarely, 3-sometimes, 4-often, 5-“I have influence" (almost always), the Questionnaire consisted of 7 question. Cronbach's Alpha for that tool was .87.

Tool for Investigating Expected Changes. The direct question in questionnaire allows one to investigate the expected direction of life changes within 1 year, 2 years and 5 years. The respondents estimated the possibility of changes in particular spheres of life, such as health, career and family life. They defined the direction and intensity of changes with the 0 to 5 scale, where 0 meant that their life (in that particular sphere) would change for the worse, 1-would not get better, i.e. remain the same, 2-would slightly get better, 3-would get better, 4-would substantially get better, 5-was definitely going to get better. The tool included12 question. Cronbach's Alpha for that tool was .73.

The Self-esteem Scale (Rosenberg, 1966), with four additional dimensions of self-description added, as proposed by Dettinger \& Hart (2007). The respondent described to what degree he or she possessed certain traits and abilities, such as: attractiveness, sociability, diligence, intelligence, responsibility, honesty, independence, self-assurance and protectiveness, as well as ability to communicate and write business letters and CVs. The scale contained 12 items. Self-esteem was measured used scale from 1 to 5 , where 1 meant "I do not possess that trait/skill at all” to 5 "I possess that trait/skill to a very high degree”. Cronbach’s Alpha for that tool was .84.

\subsection{The Study Group}

The study was carried out in two sub-groups of persons aged between 18 and 35. Members of the first sub-group (proper study participants) were recruited from among all the beneficiaries of the project carried out by the selected Family Aid Centre through purposive sampling based on the criterion of age $(\mathrm{N}=321)$. Those were unemployed persons using social welfare in their young adulthood. Project recruitment was continuous and it was advertised on the radio and in local press. When accepting the application from an interested person, the recruiting employee 
talked to the applicant and noted down contact details, and also verified documents confirming eligibility for participation in the project. After positive qualification, the welfare employee working for the project invited the candidate for an interview. At that moment, the co-operation between the participant and the welfare employee responsible for conducting the participant's individual reintegration path would commence.

Control group consisted of persons at the same developmental level, coming from the same district. The selection was based on age (18 - 35), the fact of unemployment and the condition of not using the assistance of any welfare institution $(\mathrm{N}=200)$. The researcher tried to make the gender structure of the control group similar to that of the study group (see Table 1).

The total number of participants was 521, of which 62\% were project beneficiaries (321) and 38\% were members of the control group (200).

\section{Study Results}

\subsection{Comparison between Groups}

In order to verify Hypothesis 1 related to differences between beneficiaries and control group members, comparisons of selected traits were carried out, with the Anova test used to compare mean values between the two groups (the adopted significance level was alpha $=.05$ ).

\subsection{Expectation of Changes}

Respondents from the control group expected positive changes within 1, 2 or 5 years and in the general perspective. They most often expected changes to occur in the family sphere and financial situation in the perspective of 2 and 5 years. As for health and professional life, the most frequent answers (70\%) of control group members were- "it is not going to get better" or "it will get slightly better".

Meanwhile, persons from the study group indicated the answer "it will not get any better" in all spheres, in the perspective of 1 year, 2 years and 5 years. The only exception was the sphere of social life, where the respondents expected similar changes as the persons from the control group.

The statistical difference related to future expectations between the groups was statistically significant for expecting change in general and expected changes in family and health within 5 years (Table 2).

\subsection{Self-Esteem}

The results of conducted statistical analyses indicate that self-esteem related to intelligence was significantly lower among persons from the study group than among persons from the control group (Table 3), while the level of such traits as protectiveness, responsibility, independence and self-assurance was higher in the study group than in the control group.

\subsection{Sense of Control over One's Life}

Persons from the control group had much stronger sense of control over their lives in the financial sphere, professional sphere, relations with the partner, relations with other people and in the sphere of own health than

Table 1. Demographic characteristic of groups.

\begin{tabular}{ccccc}
\hline & Age & Women & Men & \\
\hline & $15-18$ & 27 & 30 & $57(18 \%)$ \\
Study group & $19-25$ & 82 & 69 & $151(47 \%)$ \\
& $26-35$ & 55 & 48 & $113(35 \%)$ \\
& Total & & & $321(100 \%)$ \\
\hline \multirow{3}{*}{ Control group } & $15-18$ & 18 & 18 & $36(18 \%)$ \\
& $19-25$ & 57 & 44 & $101(50 \%)$ \\
& $26-35$ & 32 & 31 & $63(32 \%)$ \\
& Total & & & $200(100 \%)$ \\
\hline
\end{tabular}


Table 2. Expecting changes in the perspective of 5 years-differences between the groups.

\begin{tabular}{|c|c|c|c|c|c|}
\hline Changes & Sum of squares & $\mathrm{df}$ & Mean square & $\mathrm{F}$ & $p$ \\
\hline General & 18.72 & 15 & 1.25 & 2.28 & .004 \\
\hline Social life & 50.14 & 15 & 3.34 & 1.51 & .096 \\
\hline Health & 44.71 & 14 & 3.19 & 3.13 & .0001 \\
\hline Professional life & 2.64 & 11 & .24 & .95 & .49 \\
\hline Family life & 52.09 & 15 & 3.47 & 1.834 & .03 \\
\hline
\end{tabular}

Source: own study.

Table 3. Self-evaluation of the degree of possessing a given trait or skill—differences between the groups.

\begin{tabular}{ccccc}
\hline Trait & df & Mean square & F & $p$ \\
\hline Intelligence & 1 & 1.69 & 4.19 & .041 \\
Protectiveness & 1 & 2.92 & 7.53 & .006 \\
Responsibility & 1 & 7.25 & 18.42 & .0001 \\
Independence & 1 & 7.38 & 14.6 & .001 \\
Self-assurance & 1 & 1.69 & 4.19 & .041 \\
\hline
\end{tabular}

Source: own study.

persons from the study group (cf. Table 4). It should be stressed that young people from both groups displayed a similar level of evaluation in such spheres as appearance, ways of spending free time and family relations.

\subsection{Evaluation of the Impact of Events on One's Life}

Persons from the study group evaluated events considered normative in early adulthood (choice of life partner, school graduation, starting the first job) as more positive than members of the control group (Farnicka, 2014).

\subsection{Comparison of the Study Group before and after the Participation in the Project}

In order to verify Hypothesis 2, which assumed that changes are bound to occur among project participants in the form of increased self-esteem, increased sense of control over one's life, increasingly positive evaluation of events and future expectations, an analysis was carried out twice: before project commencement and three months after its completion. Most differences were found in the areas of expected changes, evaluation of the impact of events on one's life and sense of control over various aspects of life. To investigate the differences, $t$ statistics for dependent groups was used.

\subsection{Self-Esteem}

Both before and after the project the respondents indicated mean values for the investigated personality traits (mean 3.5 on a 0 to 5 scale). However, one should note the changes that occurred between the first and the second evaluation. After the programme, differences were noted in the participants' responses in the following areas: evaluation of own intelligence, diligence, protectiveness, responsibility, independence, honesty (Table 5). It should be noted that some of the changes consisted in decreased self-evaluation of the intensity of personal traits. This related practically to all the variables with the exception of intelligence.

\subsection{Knowledge and Skills}

Respondents perceived themselves as possessing increased knowledge and skills in the following areas: knowledge of personal rights in the employment context, job-seeking skills and CV writing skills. However, their evaluation of their communicative skills lowered as a result of the project (Table 6). 
Table 4. Sense of control over one’s life-differences between the groups.

\begin{tabular}{ccccc}
\hline Sphere & df & Mean square & F & $p$ \\
\hline Free time & 1 & 1.14 & .41 & .52 \\
Family relations & 1 & .64 & .22 & .64 \\
Appearance & 1 & 1.96 & .68 & .41 \\
Health & 1 & 7.38 & 14.62 & .01 \\
Finances & 1 & 2.92 & 7.53 & .006 \\
Relations with others & 1 & 7.38 & 14.62 & .001 \\
Relations with the partner & 1 & 7.25 & 18.42 & .001 \\
Professional life & 1 & 1.69 & 4.19 & .04 \\
\hline
\end{tabular}

Source: own study.

Table 5. Differences in self-esteem related to the intensity of personal traits as a result of the conducted programme.

\begin{tabular}{|c|c|c|c|c|c|c|c|}
\hline \multirow{2}{*}{ Self-esteem } & \multirow{2}{*}{$\begin{array}{l}\text { intensity of a trait in the } \\
1^{\text {st }} \text { and } 2^{\text {nd }} \text { evaluation }\end{array}$} & \multicolumn{3}{|c|}{ Differences in dependent samples } & \multirow[t]{2}{*}{$\mathrm{t}$} & \multirow[t]{2}{*}{ df } & \multirow[t]{2}{*}{$p$} \\
\hline & & Mean & SD & SE & & & \\
\hline Intelligence 1-Intelligence 2 & $3.23-3.31$ & -.08 & .75 & .04 & -2.18 & 434 & .03 \\
\hline Diligence 1-Diligence 2 & $3.58-3.47$ & .1 & .83 & .04 & 2.59 & 439 & .01 \\
\hline Protectiveness1-Protectiveness 2 & $3.58-3.50$ & .08 & .81 & .04 & 2.09 & 437 & .04 \\
\hline Responsibility 1-Responsibility 2 & $3.62-3.51$ & .10 & .80 & .04 & 2.67 & 434 & .01 \\
\hline Independence 1-Independence 2 & $3.56-3.47$ & .09 & .86 & .04 & 2.19 & 434 & .03 \\
\hline Honesty 1-Honesty 2 & $3.59-3.50$ & .09 & .84 & .040 & 2.47 & 433 & .01 \\
\hline
\end{tabular}

Table 6. Evaluation of the level of knowledge and skills.

\begin{tabular}{|c|c|c|c|c|c|c|c|}
\hline \multirow{2}{*}{ Knowledge and skills } & \multirow{2}{*}{$\begin{array}{l}\text { Level of knowledge and skills } \\
\text { in the } 1^{\text {st }} \text { and } 2^{\text {nd }} \text { measurement }\end{array}$} & \multicolumn{3}{|c|}{ Differences in dependent samples } & \multirow{2}{*}{$\mathrm{t}$} & \multirow{2}{*}{ df } & \multirow{2}{*}{$p$} \\
\hline & & Mean & SD & SE & & & \\
\hline $\begin{array}{l}\text { Knowledge of rights } \\
\text { 2-knowledge of rights } 1\end{array}$ & $3.10-3.06$ & .24 & 1.12 & .066 & 3.52 & 277 & .001 \\
\hline $\begin{array}{c}\text { Job-seeking skills } \\
\text { 2-job-seeking skills } 1\end{array}$ & $2.91-2.68$ & .13 & 1.19 & .06 & 2.19 & 383 & .03 \\
\hline $\begin{array}{l}\text { Communication skills } \\
\text { 1-communication skills } 2\end{array}$ & $3.46-3.36$ & .10 & .84 & .04 & 2.58 & 430 & .01 \\
\hline $\begin{array}{l}\text { CV writing skills } 2-\mathrm{CV} \\
\text { writing skills } 1\end{array}$ & $2.68-2.55$ & .24 & 1.12 & .07 & 3.77 & 298 & .0001 \\
\hline
\end{tabular}

\subsection{Evaluation of the Influence of Life Events}

In the evaluation of life events, an important change was noted for the area of professional life and evaluation of professional activity. The evaluation of all the events that changed related to the increase of their positive impact on life. Evaluations have gone up, which means that as a result of the project young men and women considerably changed their perception of those events. This may indicate that they have become more open to changes and that in the future they will be able to make more frequent attempts to change their professional situation (Table 7). The result may also indicate that political activity is one of the manifestations of social engagement.

\subsection{Sense of Control over One's Life between Groups}

The conducted study reveals that the sense of control only increased in the area of control over finances (student's $\mathrm{t}$, mean in the $1^{\text {st }}$ measurement 5.1 ; in the $2^{\text {nd }}$ measurement 5.53; mean difference $=-.59, \mathrm{t}=-2.211$, 
Table 7. Differences in the evaluation of impact of events on life.

\begin{tabular}{|c|c|c|c|c|c|c|c|c|c|}
\hline \multirow[t]{3}{*}{ Evaluation of impact } & \multirow{3}{*}{$\begin{array}{l}\text { Result of evaluation in } \\
\text { the } 1^{\text {st }} \text { and } 2^{\text {nd }} \\
\text { measurement }\end{array}$} & \multicolumn{5}{|c|}{ Differences in dependent samples } & \multirow[t]{2}{*}{$\mathrm{t}$} & \multirow[t]{2}{*}{ df } & \multirow[t]{3}{*}{$p$} \\
\hline & & \multirow[t]{2}{*}{ Mean } & \multirow[t]{2}{*}{ SD } & \multirow[t]{2}{*}{ SE } & \multicolumn{2}{|c|}{$\begin{array}{l}\text { 95\% Confidence } \\
\text { Interval for the } \\
\text { mean difference }\end{array}$} & & & \\
\hline & & & & & $\begin{array}{l}\text { Lower } \\
\text { limit }\end{array}$ & $\begin{array}{l}\text { Upper } \\
\text { limit }\end{array}$ & & & \\
\hline $\begin{array}{l}\text { Political activity 1- } \\
\text { Political activity } 2\end{array}$ & $4.61-4.88$ & -.27 & 2.22 & .11 & -.48 & -.06 & -2.5 & 422 & .01 \\
\hline $\begin{array}{l}\text { Loss of job 1- } \\
\text { loss of job } 2\end{array}$ & $2.32-2.64$ & -.32 & 2.89 & .14 & -.6 & -.04 & -2.25 & 411 & .03 \\
\hline $\begin{array}{l}\text { Change of job 1- } \\
\text { Change of job } 2\end{array}$ & $5.43-5.71$ & -.28 & 2.31 & .11 & -.5 & -.06 & -2.48 & 416 & .01 \\
\hline
\end{tabular}

$\mathrm{df}=246, p<.05)$. This may indicate that some motivation to act and to change one's professional and personal situation was indeed stimulated in project participants, but unfortunately that motivation seemed to be limited, as no changes in the sense of control over professional, personal and social life, health, appearance and leisure time were noted.

\subsection{Expecting Changes}

Respondents expected their lives to change in every case; over $70 \%$ of them expected their life to change slightly or significantly in the future (only in perspective of 2 years). Those expectations were higher after the programme completion than before its commencement. In the evaluation of expected changes, women were generally more optimistic. Before the programme more women than men expected things to change. After the programme those evaluations were no longer gender-dependent, which means that the level of expectation and motivation related to changes in life has risen in the male respondents group (Table 8).

Below are the results of investigating the predictors of change of expectations towards the future in the sphere of professional life (Table 9). The significant variables for that variable were participants' age, sense of dignity and the acquired skills of job-seeking (cf. Table $8, \mathrm{R}^{2 \text { model2 }}=.81, \mathrm{~F}=8.02, p<.0001$, hierarchic regression analysis). This means that, along with the participant's age, expectations were less positive. Meanwhile, jobseeking skills and honesty remained in a positive correlation.

\section{Discussion}

On the basis of the obtained study results one can conclude that the participation in the project not only raised the level of life competencies or professional skills of the participants but noticeably motivated them to change the way in which they functioned, both with regard to time management and in the social dimension connected with entering into new relations and assuming increased responsibility. Other observed results were the increased sense of control over one's life in various aspects, improvement of communicative skills, making selfevaluation closer to reality, recognition of one's competencies and improvement of professional qualifications. The obtained differences between project beneficiaries and persons from the so-called social majority constituting the control group in the analysed areas confirmed the assumptions about the existence of such differences. The study group members differed significantly from the control group in their lack of expectation of any changes, heightened self-esteem in selected dimensions, more positive evaluation of normative events on their lives and lower sense of control over their lives. That result justifies a conclusion that the choice of the control group was correct, as the results obtained differ from the classic results obtained in studies of differences between volunteers and non-volunteers recruited for research (Shaughnessy, Zechmeister, \& Zechmeister, 2002). Also, in line with the adopted assumptions, a picture of differences for specific personal traits was obtained. Intelligence was evaluated lower, while other traits higher than in the control group. That phenomenon-heightened self-esteem for personal traits, a more positive evaluation of events connected with one's own past life-may indicate the existence of a defense mechanism that is to serve the purpose of ignoring the differences between "us" and "them/others". That mechanism allows a person to value his or her own world and not generate any 
Table 8. Change of expectations concerning the future (within 2 years’ time perspective).

\begin{tabular}{|c|c|c|c|c|c|c|c|c|c|}
\hline \multirow{3}{*}{$\begin{array}{l}\text { Expectation of changes } \\
\text { in } 2 \text { years }\end{array}$} & \multirow{3}{*}{$\begin{array}{l}\text { Level of expectation in the } \\
1^{\text {st }} \text { and } 2^{\text {nd }} \text { measurement }\end{array}$} & \multicolumn{5}{|c|}{ Differences in dependent samples } & \multirow{3}{*}{$\mathrm{t}$} & \multirow{3}{*}{$\mathrm{df}$} & \multirow{3}{*}{$p$} \\
\hline & & \multirow{2}{*}{ Mean } & \multirow{2}{*}{ SD } & \multirow{2}{*}{ SE } & \multicolumn{2}{|c|}{$\begin{array}{l}\text { 95\% Confidence Interval } \\
\text { of the mean difference }\end{array}$} & & & \\
\hline & & & & & Lower limit & Upper limit & & & \\
\hline $\begin{array}{l}\text { Professional life 1- } \\
\text { professional life } 2\end{array}$ & $1.62-2.65$ & -1.03 & 1.46 & .070 & -1.16 & -.90 & -15.79 & 496 & .001 \\
\hline Family life 1 -family life 2 & $2.35-2.80$ & -.45 & 1.33 & .06 & -.57 & -.33 & -7.46 & 490 & .001 \\
\hline
\end{tabular}

Table 9. Determinants of changes in expectations towards professional life.

\begin{tabular}{|c|c|c|c|c|c|c|c|c|c|}
\hline & \multirow{2}{*}{ Model } & \multicolumn{2}{|c|}{$\begin{array}{l}\text { Non-standardized } \\
\text { coefficients }\end{array}$} & \multirow{2}{*}{$\begin{array}{c}\begin{array}{c}\text { Standardized } \\
\text { coefficients }\end{array} \\
\text { Beta }\end{array}$} & \multirow{2}{*}{$\mathrm{t}$} & \multirow{2}{*}{ Significance } & \multicolumn{3}{|c|}{ Correlations } \\
\hline & & B & $\begin{array}{l}\text { Standard } \\
\text { error }\end{array}$ & & & & Zero & Partial & $\begin{array}{c}\text { Partial } \\
\text { (semi-partial) }\end{array}$ \\
\hline \multirow{3}{*}{1} & (Constant) & 2.287 & .358 & & 6.389 & .000 & & & \\
\hline & Participant's age & -.147 & .048 & -.156 & -3.047 & .002 & -.155 & -.157 & -.156 \\
\hline & Honesty 1 & .208 & .091 & .118 & 2.302 & .022 & .116 & .119 & .118 \\
\hline \multirow{4}{*}{2} & (Constant) & 2.264 & .430 & & 5.270 & .000 & & & \\
\hline & Participant's age & -.145 & .047 & -.155 & -3.076 & .002 & -.155 & -.159 & -.155 \\
\hline & Honesty 1 & .257 & .090 & .146 & 2.852 & .005 & .116 & .148 & .143 \\
\hline & Job-seeking skills 2 & .216 & .060 & .185 & 3.612 & .000 & .154 & .186 & .182 \\
\hline
\end{tabular}

expectations towards the future. Project beneficiaries participating in the study were also characterized by low expectations towards the future and low sense of control over their lives. That specific combination of features (high self-esteem of personal traits, positive evaluation of life events, no expectations towards the future and low sense of control over one's life in the professional and economic sphere) could be considered as a characteristic difference between persons considered marginalized and persons well adapted to the society (Checkland, 1997).

On the other hand, similarities in the two sub-groups should be stressed, relating to social life, own health and appearance. Those spheres, important for that age from the developmental point of view, received similar evaluations in the two groups. This may mean that the differences between the two groups result from the specific conditions prevailing in the socialization environment. Current problems connected with developmental tasks are evaluated in a similar way (e.g. influence on one's physical appearance).

On the basis of the obtained study results one can find out the significance of participation in proposed training and workshops for the change of expectations towards professional life in the perspective of 2 years and family life in the perspective of 2 years. The observed change mainly related to personal traits and competencies/skills connected with the professional sphere of life, such as intelligence, responsibility, independence, honesty and diligence, knowledge of one's rights, and CV writing. Obviously, these traits are also vital in everyday life. The change of evaluation of the impact on one's life was also mainly found for job-related events and political activity and control over financial situation.

The obtained differences (even in the form of the drop in the degree of possessed traits or skills) should be treated as a symptom of change of self-image and making it more real. This particularly refers to self-esteem (features such as responsibility, independence, diligence). That aspect was indicated by Goryńska, Winiewski, \& Zajenkowski (2015), who emphasized the importance of the processes of self-deception for defending the self. Those mechanisms, operating as idealisation, reaction formation patterns, or for instance fantasizing and isolating oneself, are purposeful. Thus, one can conclude that those mechanisms sustain well-being of an individual making him or her oblivious to the differences between his or her group and the group of others and eliminating 
discomfort stemming from the differences between the "real self" and the "ideal self". Long-term use of those defence mechanisms leads to inadequate evaluation of reality. The activating significance of perceiving the difference between the ideal self and the real self may be analysed from the point of view of Higgins' concept of self-discrepancy (Higgins, 1996; Bąk, 2002).

As for changes connected with participation in the project that occurred in the dimensions of social knowledge and self-knowledge, differences have been noted that authorize one to draw a conclusion that as a result of active participation in the project the respondents' real self-appraisal increased and therefore they came into closer contact with their environment and the reality. As a consequence of the project, they considerably changed their perceptions in the field of evaluation of selected events, as well as self-esteem and sense of control. The changes introduced by the project, i.e. the time and space organization and the necessity to exchange information, made the participants’ motivation level change as well (Barrett \& Kurzban, 2006; Rongińska, 2012).

\subsection{Prediction and Significance of the Training}

On the basis of the obtained results for predictors of changes in professional life expected within the period of 2 years, we may note that no predictors were found there from the sphere of event evaluation or sense of control. Age was found to be the most significant (the younger the participants, the more they expected positive change), followed by honesty and job-seeking skills. Thus on the basis of the research results one can indicate that despite the significance of work on reality perception for the change of expectations towards the future professional life, the crucial thing was the change in job-seeking skills and age. The obtained results are in line with the existing knowledge of the flexibility of young people and their greater motivation for change and the importance of teaching them professional competencies. Bearing in mind the age of the study and project participants, selfimprovement and achieving new professional competencies were considered essential. The period of young adulthood is the time of preparing for and undertaking various professional, social and family roles. From the point of view of the development of professional identity, the key value of the project was that it offered the participants the opportunity to think about themselves as employees and the opportunity to train in the profession (Erikson, 2004). On the other hand, the connection between the change of events evaluation plus the sense of control and the change of expectations has not been confirmed.

\subsection{Limitation of the Study}

The researcher is well aware of the difficulties connected with the selection of the control group for the beneficiaries of the District Family Aid Centres as described in literature. Therefore there was no volunteer access to the control group; instead, the persons selected were the ones who were the most similar to the study group members and who passed the selection criterion. The study was conducted following the research plan with the control group, with initial measurement of the dependent variable in various groups. In order for that procedure not be confused with a full experimental plan, in the description of results it is indicated that the control group only served the purpose of comparing the level of analysed traits among participants and non-participants of the project before project realization.

\section{Conclusion}

The observed and analysed changes in the dimensions of social awareness and self-knowledge before and after participation in the project indicate that the project gave the respondents the improved ability to evaluate themselves realistically and closer contact with the environment, thus offering them an opportunity to change. Overall, project participants displayed high levels of motivation to act and, as a result of regular participation in the classes chosen by them, they experienced many changes in different areas of life.

The changes stimulated by the participation in the described project may be an example of a good practice of supporting the process of integration of people coming from groups/enclaves considered to be minorities in their local environment. It could be noticed as the first step from "illegality" to be a part of society (Ambrosini, 2016).

The project results demonstrate that preventive work should concentrate on shaping and offering multi-dimensional support to the individual. This may trigger the processes of self-perception (i.e. perceiving the difference between the declared and the real self). Also, attention should be paid to activities from the sphere of professional knowledge that may tangibly increase the level of necessary professional skills. Such an activity may 
trigger a sequence of recognition and bring about real change in both perception and functioning.

In conclusion, it is worthwhile to note the need of including adults from a difficult socio-cultural environment in programmes that combine knowledge, practical useful skills and good psychological experience (self-esteem, communication, new group). Such programmes could improve competencies to protect social capital of societies.

Creating a social climate that encourages differences and diversity entails permission for the demonstration of conflicts, the revealing of which makes it possible to transcend hitherto prevailing stereotypes and trigger the sequence of cognitions (perception of real differences and similarities) that at last enables the search for common aims and tasks. Without awakening the real need to change, neither the best professional programmes nor the best specialists will achieve the intended effects. Openness, curiosity and stimulating the need to change through diminishing the distance are one of the key prerequisites for co-existence and transfer of knowledge, skills and joint co-functioning of many cultures in the future perspective.

\section{References}

Ajzen, I. (1991). The Theory of Planned Behavior. Organizational Behavior and Human Decision Processes, 50, $179-211$. http://dx.doi.org/10.1016/0749-5978(91)90020-T

Ambrosini, M. (2016). From “Illegality” to Tolerance. International Migration, 54, 144-159. http://dx.doi.org/10.1111/imig.12214

Bąk, W. (2002). Higgins’s Theory of the “Self” Discrepancy. Przegląd Psychologiczny (Psychological Review), 45, 39-55.

Banks, J. A. (2008). Diversity, Group Identity and Citizenship Education in a Global Age. Educational Researcher, 37, 129139. http://dx.doi.org/10.3102/0013189X08317501

Barrett, H. C., \& Kurzban, R. (2006). Modularity in Cognition: Framing the Debate. Psychological Review, 113, 628-647. http://dx.doi.org/10.1037/0033-295X.113.3.628

Bennett, M. (1986). A Developmental Special Issue on Intercultural Training. International Journal of Intercultural Relations, 10, 65-72. http://dx.doi.org/10.1016/0147-1767(86)90005-2

Berry, J. W., Poortinga, Y. H., Breugelmans, S. M., Chasiotis, A., \& Sam, D. L. (2011). Cross-Cultural Psychology: Research and Applications. UK: Cambridge University Press. http://dx.doi.org/10.1017/CBO9780511974274

Boszkiewicz, H. (1997). Reability of Non Clasical Tests. Bydgoszcz: Institute of Psychology.

Cervone, D., \& Pervin, L. (2013). Personality: Theory and Research. New York: Wiley and Sons.

Checkland, P. (1997). Systems Thinking, Systems Practice. Chichester: John Wiley \& Sons, Ltd.

Dettinger, S., \& Hart, G. (2007). The Relationship between Self-Esteem and Indirect Aggression in the Workplace. Journal of Psychiatry and Psychology, 1, 1-8.

Erikson, E. H. (2004). Identity and Life Cycle. Poznań Zysk i S-ka.

Farnicka, M. (2014). Future Perspectives as a Condition of Positive Adaptation of Young Adults after Traumatic Experience. Current Issues in Personality Psychology, 2, 164-170. http://dx.doi.org/10.5114/cipp.2014.46232

Goryńska, E., Winiewski, M., \& Zajenkowski, M. (2015). Situational Factors and Personality Traits as Determinants of College Students' Mood. Personality and Individual Differences, 77, 1-6. http://dx.doi.org/10.1016/j.paid.2014.12.027

Grzymała-Moszczyńska, J. (2013). The Cultural Distance and Acculturation. In B. Bosak-Herbst, M. Głogowska-Grajer, \& M. Kowalski (Eds.), Antropologiczne Inspiracje (pp. 228-251). Warsaw: UW.

Higgins, E. T. (1996). The "Self Digest”: Self-Knowledge Serving Self-Regulatory Functions. Journal of Personality and Social Psychology, 71, 1062-1083. http://dx.doi.org/10.1037/0022-3514.71.6.1062

Lindquist, K., \& Barret L .F. (2008). Constructing Emotion: The Experience of Fear as a Conceptual Act. Psychological Science, 19, 898-903. http://dx.doi.org/10.1111/j.1467-9280.2008.02174.x

Pagani, C., \& Robustelli, F. (2010). Young People, Multiculturalism and Educational Interventions for the Development Empathy. International Social Science Journal, 200-201, 247-261.

http://dx.doi.org/10.1111/j.1468-2451.2011.01761.x

Rongińska, T. (2012). Psychologiczne uwarunkowania poczucia sukcesu w pracy. Problemy Profesjologii, 2, 27-35.

Rosenberg, M. (1966). SES. http://www.practest.com.pl/files/SES_arkusz.pdf downloaded 20.10.2013

Shaughnessy, J., Zechmeister E., \& Zechmeister, J. (2002). Research Methods in Psychology (5th ed.). Gdansk: GWP.

Stratton, P. (2010). The Evidence Base of Systemic Family and Couples Therapy. UK: Association for Family Therapy. www.aft.org.uk

Trempała, J. (2002a). The Time and the Change. Bydgoszcz: AB Press. 
Trempała, J. (2002b). Models of Psychological Time in the Research on Time Perspectives. In J. Trempała, \& L.-E. Malmberg (Eds.), Adolescents’ Future-Orientation: Theory and Research (pp. 111-122). Frankfurt am Main: Peter Lang.

Weber, M. (2002). Economy and Society: An Outline of Interpretive Sociology. In N. W. Biggart (Ed.), Readings in Economic Sociology (pp. 3-4). Oxford: Blackwell Publishers Ltd.

\section{Submit or recommend next manuscript to SCIRP and we will provide best service for you:}

Accepting pre-submission inquiries through Email, Facebook, Linkedin, Twitter, etc A wide selection of journals (inclusive of 9 subjects, more than 200 journals)

Providing a 24-hour high-quality service

User-friendly online submission system

Fair and swift peer-review system

Efficient typesetting and proofreading procedure

Display of the result of downloads and visits, as well as the number of cited articles

Maximum dissemination of your research work

Submit your manuscript at: http://papersubmission.scirp.org/ 